\title{
AGUJAS QUE HABLAN: \\ LAS ARPILLERISTAS CHILENAS
}

\author{
POR \\ MARJORIE AGOSIN \\ Wellesley College
}

Bordar, tejer, planchar, artesanias domésticas femeninas, han sido y siguen siendo, a través de la historia, medios de expresión vital para la mujer en los cuartos de costura de las grandes casonas o en las trastiendas de las rucas de adobe donde silenciosas trabajan.

La mujer, silenciosa por tradición, está más cerca de la escritura, porque su acceso al habla ha sido marginal. Siempre al igual que su relación con los discursos masculinos establecidos y como ruta de evasión, la mujer. borda/escribe. Remontándonos a la mitología griega, basta:recordar al rey Teseo, casado con Procne, que se enamora de su cuñada Filomena. Después de violarla, le corta la lengua para prohibir su discurso hablado. Sin embargo, Filomena borda en un tapiz lo acontecido y se lo envía a su hermana.

El coser, tejer, bordar, son y representan escrituras femeninas que cuentan lo que la palabra o el habla no pueden decir. Estas artes representan escrituras que utilizan el cuerpo mismo como medio de moldear esta expresión: dedos, uñas, brazos. Así, las mujeres que bordan o cosen abandonan el rol tradicional de consumidoras de arte para convertirse en productoras que trascienden ese orden que las relegó a la marginalidad para incorporarse activamente al proceso de producción de la cultura.

Es éste el fenómeno de las arpilleristas chilenas, quienes, utilizando un arte netamente doméstico - por lo de ama de casa y por ser ejecutado dentro del limitado perímetro del hogar-, cobran una fuerte tonalidad subversiva y testimonial dentro y fuera de Chile. En consecuencia, la imagen de la dócil ama de casa que trabaja pacientemente con retales y coloca armoniosamente los diseños superpuestos en una tela ordinaria, invierte: radicalmente su función social, transformando a este arte pasivo en una 
activa protesta donde la mujer, por medio de su propia escritura, crea una dinámica vital en la historia de su país.

Para entender el texto y contexto de la arpillera chilena conviene recordar que a partir del derrocamiento del gobierno constitucional de Salvador Allende, en 1973, se inicia en la historia chilena - historia caracterizada por una rica tradición democrática- una época donde la represión cultural, política y económica empaña el desarrollo del país ${ }^{1}$.

Sin embargo, la represión impuesta por la ideología dominante no siempre logra su anhelado resultado. Un ejemplo revelador es el contenido de la arpillera, creación de carácter popular y de temática delineada para resistir y protestar contra la dictadura militar.

El discurso de la arpillera no es especulativo ni teórico, es concreto y vivencial, centrado en una costura específica que, por medio de códigos perfectamente descifrables, testimonia lo que la voz no puede exclamar, o como en un textum literario, las arpilleras cuentan una historia. Los diversos colores son capítulos imprescindibles, cuyos objetivos centrales residen en la composición de ciertos detalles: árboles verdes, una mujer sola, prisioneros, alambres de púa, soles inmensos, cordilleras vacilantes ${ }^{2}$.

Por medio de los rústicos hilos se preserva una memoria colectiva, escrita-cosida por aquellas anónimas y tantas veces ignoradas mujeres. Ellas, al dar cada puntada, se arriesgan, al igual que la escritora que en cada palabra se atreve a ser ella y a decir su verdad.

Las arpilleristas del Chile actual son mujeres que viven en poblaciones marginales en las afueras de la capital, Santiago. En la mayoría sus edades fluctúan entre los veinticinco y los cincuenta años. A partir del año 1974 las arpilleristas comienzan a organizarse en talleres auspiciados por la Vi-

1 Para mayor información sobre la opresión cultural en el Chile de hoy, véanse los estudios panorámicos de Jaime Concha, «Testimonios de la lucha antifascista», Araucaria (Madrid, España, núm. 4, 1978, pp. 129-147). En inglés véase el número especial de Review 27, dedicado a la cultura chilena, publicado por el Center for Inter-American Relations, NY, NY. También en inglés, véase la colección de cuentos Chilean Writers in exile (Trumanburg, NY: The Crossing Press, 1980).

${ }^{2}$ Hasta la fecha, los trabajos de investigación o de difusión cultural dedicados a las arpilleras son prácticamente nulos, al igual que el arte poblacional. Los únicos existentes hasta la fecha son: "Reportaje» Arte Poblacional: cuestión de coraje ( $L a$ Bicicleta, Santiago de Chile, diciembre 1979), p. 25.

El único estudio detallado sobre las arpilleras hasta la fecha es el de Eliana Moya Raggio, "Las arpilleras: cultura chilena de la resistencia» (en Literatura chilena: Creación y crítica, julio-septiembre 1982, núm. XXI, Los Angeles, California), p. 205. También se puede obtener mayor información sobre las arpilleras por medio del Chile Committee for Human Rights, con sede en Nueva York. Para un estudio panorámico sobre las artes plásticas en Chile, véase Nanda Leonardini, Chile: $E l$ arte de la resistencia (en Plural, México, núm, 20), pp. 15-20, 
caría de la, Solidaridad ${ }^{3}$. Dada la marginalidad y extrema pobreza en que estas mujeres viven, la Vicaría decide prestarles ayuda con un local para reunirse y trabajar en la creación de sus arpilleras. La función primordial de la arpillera producida hoy en Chile nace de una necesidad vital y urgente: el hambre. Se confecciona y se vende la arpillera para poder alimentar a hijos de padres muertos, desaparecidos o para suplementar la exigua suma de dinero obtenida con el salario mínimo.

Mencionamos que la arpillera es una necesidad específica y muy ligada al Chile de hoy. Sin embargo, no hay que olvidar que la arpillera nace en los bordados de lana de Violeta Parra durante los años sesenta. Bordados naif, donde la folklorista, pintora y arpillerista dibuja escenas de la vida diaria de su pueblo. La tradición iniciada por Violeta se continúa en las bordadoras de Isla Negra, una caleta de pescadores a una hora de Santiago. Motivadas por problemas económicos, un grupo de esposas de pescadores se dedican a bordar, durante los inviernos, con candor y sencillez, escenas cotidianas: una mujer amasando pan, una iglesia rodeada de niños, la caleta del pueblo... Pablo Neruda, quien inmortalizó Isla Negra en sus poemas, habla de las bordadoras en su libro Para nacer he nacido:

En este último invierno comenzaron a florecer las bordadoras de la Isla Negra. Cada casa de las que conocí desde hace treinta años, sacó hacia afuera un bordado como una flor. Estas casas eran antes oscuras y calladas; de pronto se llenaron de hilos de colores, de inocencia celeste, de profundidad violenta de roja claridad. Las bordadoras eran pueblo puro y por eso bordaron con el color del corazón. Nada más bello que estos bordados, insignes en su pureza, radiantes en su alegría, que sobrepasó muchos padecimientos (p. 118) ${ }^{4}$.

Las bordadoras de Isla Negra despliegan, a través del trabajo desprovisto de aprendizaje académico, una "radiante alegría» de escenas rurales. La ruptura con esta tradición se produce en el trabajo de las arpilleristas de los barrios pobres de las afueras de Santiago; la alegre arpillera de Isla Negra contrasta con la nítida temática política y social de las arpilleras posgolpe.

Aparte de la función meramente económica de la arpillera, ésta cobra una dimensión única en la historia actual de Chile. Historia que se reelabora en la creación de estas humildes mujeres, con dibujos que testimonian vivencias de extrema urgencia y que van absolutamente ligadas a los

${ }^{3}$ La Vicaría de la Solidaridad es una institución de la Iglesia católica creada en 1976 para proteger los derechos humanos. Esta institución ha establecido comedores infantiles y defendido a prisioneros políticos.

+ Pablo Neruda, Para nacer he nacido (Barcelona: Seix Barral, 1978), p. 118. 
eventos del país. Así, encontramos arpilleras con escenas de cárceles, de comedores comunes, de niños descalzos, de masacres como la de Lonquén ${ }^{5}$, denuncias de presos políticos o sencillamente un llamado a la justicia.

A veces las arpilleras utilizan los modelos simbólicos del lenguaje para enfatizar aún más el mensaje deseado. Por ejemplo, una línea roja separa gendarmes de habitantes y una frase bordada en el costado superior de la arpillera subraya la súplica del dibujo: «Derecho a vivir en la Patria». Otra muestra una mano fuerte y liberadora; sujeta por medio de hilos multicolores y cercada por un alambre de púas, grita palabras claves: «Salud, Paz, Libertad, Justicia, Vivienda».

La aguja, las telas y el hijo se convierten en vehículos activos que transmiten un mensaje y que relatan una historia diaria. La mujer de la población, antes pasiva, sumida en el lavado y en el cuidado de numerosos hijos, se convierte en el sostén de la familia, en la fiel expositora/ participante de los males que acechan al pueblo y en valiente denunciante. La puntada ingenua de la arpillera se transforma en un testimonio de lucha y resistencia política. Cabe subrayar aquí que la aparente sencillez de la arpillera puede engañar al observador superficial, quien catalogaría este producto como un objeto de consumo turístico-folklórico. La arpillera es todo lo contrario: tanto el dibujo presentado como la arpillerista en sí representan a conciencia la resistencia al régimen opresor.

Las arpilleras son anónimas; la creadora se protege de esta manera contra la persecución patrocinada por el gobierno. Arpilleras destinadas a exhibirse en el exterior han sido detenidas en las aduanas de Chile, evitando así que un importante testimonio sobre la realidad interna del país sea juzgado en el exterior. Insistimos que la sencillez de la arpillera es aparente, y esto es claramente percibido por el gobierno de Pinochet.

El dibujo de la arpillera posee una técnica propia que se elabora y fluctúa según la destreza, la imaginación y la espontaneidad de la arpillerista. La técnica, como el contenido de la creación, nace de la necesidad, de la fantasía de cada mujer y del material disponible. En la bolsa de los retales no aparecen telas de seda, sino desechos, mortajas, pantalones de quinta mano, vendas de algún herido cercano.

5. Lonquén, pueblo en las afueras de Santiago donde se descubrieron restos de personas desaparecidas en 1978. En Lonquén se produjo un encuentro entre 'los familiares de los desaparecidos y la policía. Esto se hizo público. Para mayor información sobre esto, véase el libro de Hernán Vidal Dar la vida por la vida (Minneápolis, Minnesota: Agrupación Chilena de Familiares Detenidos Desaparecidos [Ensayo de Antropología Simbólica], Institute for the Studies of Ideologies and Literature, 1982). 
De esta bolsa, humilde en su contenido, las mujeres, reunidas en diferentes comunas como la de Puente Alto, La Pincoya, La Hermida, Villa O'Higgins, se reúnen colectivamente para discutir la temática de la obra y ver que el tema sea realista. Pero cada una trabaja individualmente sumida en su mosaico de retazos. Si bien los temas de las arpilleras guardan muchos rasgos comunes, como la escasez de agua, el comedor común de la vecindad rodeado por ollas y mesas vacías, no obstante cada mujer le otorga a su trabajo un colorido propio, una intuición poética de sus alrededores y muchas veces personaliza aún más su creación con un pequeño mensaje escrito en un diminuto bolsillo al reverso de la arpillera destinado al ser querido, al desaparecido o simplemente un mensaje de paz.

Generalmente, la tela inicial o tela de fondo de la arpillera está hecha de sacos de papa, de harina o de azúcar. Sobre esta tela se superponen y. se cosen figuras en relieve, ventanas que se abren o ventanas imaginadas, ya que muchas viviendas en estas poblaciones carecen de ellas. Se incrustan en la tela árboles, iglesias, mesas, casitas pequeñas, soles de esperanza. Cada elemento es superpuesto con paciencia y cuidado para crear una visión mágica en colorido y en armonía. A veces el borde de afuera de la arpillera lleva una terminación en lana. Otras están enmarcadas por medio de puntadas simples, rústicas como la realidad evocada.

Los grupos de arpilleras están compuestos por aproximadamente veinte mujeres, aun cuando el número varía según los problemas que se presenten. Estos van desde la desesperación hasta peleas personales, creando de esta manera situaciones enormemente reales y humanas. Cada taller posee una estructura organizada. Una tesorera se encarga de distribuir las ganancias obtenidas con la venta de las arpilleras. Cada mujer recibe el dinero de su arpillera vendida y además contribuye con un cinco o un diez por ciento para el fondo común del taller. Otra mujer se preocupa por distribuir la arpillera en diversos centros y otra se preocupa de que las arpilleras estén cuidadosamente terminadas y que la temática sea de relevancia.

Un fenómeno interesante, pero no extraño, es el de que las arpilleras son prácticamente invisibles dentro del país. Son muy pocas las tiendas o centros que las exhiben, y los pocos lugares que se atreven a mostrar estas creaciones con agujas que hablan son boicoteados por la policía secreta chilena. Sin embargo, las arpilleras se llegan a exponer en los Estados Unidos y Europa, como en otros tiempos las creaciones de las bordadoras de Isla Negra se expusieron en el Museo del Louvre, en París. Dentro de Chile, las autoridades gubernamentales temen que este arte anónimo y popular incite a los observantes hacia una conciencia revolucionaria peligrosa y tratan de sustituirlo con creaciones abstractas, disfrazadas y 
desprovistas de la realidad del país. O por bordados de dudoso origen, con frases como la siguiente: «En orden y paz, Chile avanza» ${ }^{6}$.

La arpillera y la arpillerista claramente evidencian la división entre dos vertientes que marcan la cultura en el Chile de hoy. Por un lado, la arpillera trata de contrarrestar la ideología de un régimen dictatorial, y, en el campo de las artes plásticas, a aquellos artistas que trabajan en conjunción con el gobierno. Por otra parte, encontramos lo que tantas veces se denomina como una nueva cultura popular de un pueblo que no se ha dejado aniquilar. En esta tradición se inserta la arpillera chilena, que a pesar de las numerosas trabas y acechos a que es sometida, y a pesar de que circula dentro del país en un marco limitadísimo, surge aceleradamente plena de símbolos y metáforas que claman por una nueva forma de vida. Pero la arpillera ha llegado más lejos que la simple exhibición. Gracias a David Benavente y los miembros del taller de investigación de teatro de la Universidad de Chile, se ha creado colectivamente una obra que revela la vida de las arpilleristas en una población. Tres Marias y una $R o s a^{7}$ ha alcanzado gran difusión en el extranjero y ha ganado varios premios en diversos encuentros de teatro internacional. Como toda obra que refleje las agonías causadas a entes marginales por un gobierno represivo, el éxito de Tres Marías y una Rosa es una nueva fuente de preocupación para el oficialismo chileno.

El lado humano de la arpillera aflora en todo momento, pero también cabe señalar la importancia de la convivencia entre estas mujeres. Estas humildes amas de casa trabajan para subsistir y llenar esas ollas vacías que tan vívidamente aparecen en las arpilleras. También se reúnen en una actividad solidaria donde trabajan juntas, se cuentan sus males y tristezas, se toman un tecito. $\mathrm{Y}$ a la vez que con agujas e hilos militan en la tela, denuncian y se exponen a ser asediadas por la ideología dominante, que se opone a este arte que nace de la verdad y no del invento ni de la abstracción. Cada arpillera y arpillerista, lúcida de su misión, exponen el devenir político del país, las torturas, la falta de agua, el exilio. Son vivencias, escenas puestas sobre una tela que comunican visualmente lo que la palabra no puede ante un silencio impuesto.

Cada acto de repudiada violencia queda inscrito en la arpillera a través de retales, que tal vez son de un muerto querido, de un hijo desapa-

\footnotetext{
- Rótulo muy común que se ve por muchas ciudades en Chile como parte de la propaganda oficialista.

${ }^{7}$ El texto de Tres Marias y una Rosa puede leerse en Teatro chileno de la crisis institucional: 1973-1980, editado por Hernán Vidal, Carlos Ochesenius y María de la Luz Hurtado, publicada por el Institute for the Study of Ideologies and Literature (Minneápolis, Minnesota, 1982).
} 
recido... Resulta un tanto sorprendente que a pesar de la temática de clara denuncia, de desolación y hasta de desesperación, la arpillera no es lúgubre. El intenso colorido, los personajes en movimiento, los árboles verdes, el anhelo de agua fresca y la cordillera de los Andes enmarcando todas las arpilleras, transmiten una esperanza de vida distinta. Una arpillera sin la cordillera de los Andes no sería real; ésta despierta en el observador un extraño júbilo, una tierna esperanza infantil...

Los sacos de harina, azúcar, papas, cobran un encanto mágico. Imaginamos a la arpillerista trabajando, mientras una sonrisa se dibuja en sus labios, a pesar de los alambres de púas que muchas veces cercan su destino; a pesar del hambre y los amigos desaparecidos. Muchas arpilleras poseen un sol muy grande y redondo, reflejo de una energía vital que se desprende de las manos que cosen, que ríen, que sueñan. Y nosotros, los observadodes/admiradores, queremos saber más de la arpillera, de la arpi1lerista y de su espacio. ¿Cómo y cuándo confeccionó tanta maravilla de una bolsa de despojos? ¿Y cómo una mano anónima crea tanta verdad, con tanta valentía y tantos soles?

La historia elaborada/construida por retazos y residuos habla de un largo y angosto país rodeado de una inmensa cordillera y un azulado océano pacífico: esto se llama Chile. Además, la historia hecha por estas mujeres del pueblo contará de las visibles Ariadnas que con humildes hilos nos sacarán del laberinto. 
